\title{
Red Cell Distribution Width and Respiratory Diseases in Tobruk Pediatric Intensive Care Unit
}

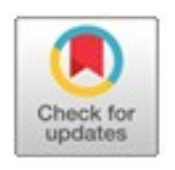

\author{
Nasren Gamal Saleh Alfraik
}

Faculty of Medicine, Pediatric Department, Tobruck University, Tobruck, Libya.

Received: 31 December 2019 /Accepted: 19 July 2020

Doi: https://doi.org/10.54172/mjsc.v35i1.225

\begin{abstract}
The red blood cell distribution width (RDW) is a simple and inexpensive parameter, which reflects the degree of heterogeneity of erythrocyte volume. This retrospective study aimed to detect the correlation between RDW and respiratory diseases and analyzed all patients admitted to the Pediatric Intensive Care Unit (PICU) at Tobruk Medical Center between January 2017 and January 2019. All patients below 16 years old with an available baseline RDW value on admission to PICU and had had a respiratory disease and needed oxygen therapy were eligible for inclusion. Of the 76 patients studied, $36.8 \%$ had elevated RDW. The median age was 97.5 days old, $60.5 \%$ were male, and 39.4\% females. All patients were Libyan and 97.4\% from Tobruk. Causes of admission were $52.6 \%$ bronchopneumonia, $29 \%$ acute broncholitis, $10.5 \%$ aspiration pneumonia, $5.3 \%$ bronchial asthma, and CHD with apnea were $2.7 \%$. We noted a respiratory retraction in most of the cases, grunting and retraction in $35 \%$, and cyanosis in $28 \%$ of cases. Reported complications of this study were sepsis $41 \%$, aspiration $24 \%$, pneumothorax $10.5 \%$, convulsion $9 \%$, apnea $8 \%$, pleural effusion $7 \%$ and renal failure $1 \% .62 \%$ of our patients had pulmonary infiltration on chest x-ray. Regarding the route of oxygen therapy, $60.5 \%$ were treated with nasal prongs, $38 \%$ with masks, and $1.3 \%$ needed a mechanical ventilator. $29 \%$ of patients received steroids. The RDW mean was 14.499 and there were significant correlations between RDW and signs of respiratory distress, length of hospital stay, and duration of oxygen therapy. $98 \%$ of our patients were discharged. We conclude there is a strong correlation between RDW and respiratory diseases as pneumonia, acute broncholitis and we recommend farther studies to study the correlation between RDW and other organ diseases in the pediatric age group.
\end{abstract}

Keywords: Red Cell Distribution Width; Respiratory Disease; Pediatric ICU.

\section{INTRODUCTION}

The red cell distribution width (RDW) is routinely reported in automated complete blood counts. It is a widely available, inexpensive, and highly reproducible test reflecting the range of the size of the circulating red blood cells (Bessman et al., 1983). Any process that releases reticulocytes in the circulation will result in an increase in RDW (Yčas et al., 2015). $\mathrm{RDW}$ in the general population is also linked with pulmonary dysfunction (Grant et al., 2003). An increase in RDW can be linked to hypoxemia. Transient decreases in oxygen par*Corresponding Author: Nasren Gamal Saleh Alfraik n.alfrek@gmail.com, Faculty of Medicine, Pediatric Department, Tobruck University, Tobruck, Libya.. tial pressures $\left(\mathrm{PaO}_{2}\right)$ will lead to a 'pulsed' erythropoietin (EPO) release through hypoxiainducible transcription factors. These will in turn trigger the release of immature reticulocytes into the circulation leading to anisocytosis and a higher RDW in the affected patient (Yčas et al., 2015). RDW is a parameter for measuring variability in red blood cell size where the normal value ranges from 11.5 to 15.5 (Zhang et al.,2013; Hunziker et al., 2012; Otero et al., 2016; Wang et al.,2011; Allen et al., 2010). Various studies have iden- 
tified RDW as a prognostic marker in community-acquired pneumonia, septic shock, acute kidney injury, pulmonary hypertension, pulmonary embolism, peripheral artery disease, and in patients with clinically significant cardiovascular disease. (Zhang et al., 2013; Hunziker et al., 2012; Otero et al., 2016).

The exact pathophysiologic explanation for why RDW can serve to be an effective indicator of mortality is not completely understood. It has been hypothesized that an increased oxidative state attributed to the release of inflammatory cytokines leads to iron immobilization, which may play a pivotal role in increasing the RDW (Zhang et al.,2013; Hunziker et al., 2012; Otero et al., 2016; Wang et al.,2011; Allen et al., 2010). RDW thereby serves as a widely available, "inexpensive prognostic marker", which if increased in a clinical setting, is suggestive of an underlying complex hyperinflammatory pathologic process (Wang et al.,2011; Allen et al., 2010; Lippi et al., 2009).

Pneumonia causes substantial morbidity in children worldwide and is a leading cause of death in children in the developing world. The occurrence of pneumonia is the highest in children under 5 years of age, and in recent years the incidence of complicated and severe pneumonia seems to be increasing. Bronchiolitis is an acute lower respiratory tract infection in early childhood caused by different viruses, with coughing, wheezing, and poor nutrition as the major symptoms (Nagakumar, \& Doull, 2011; Zorc, \& Hall, 2010). A substantial proportion of children will experience at least one episode with bronchiolitis, and as much as $2-3 \%$ of all children will be hospitalized with bronchiolitis during their first year of life (Nagakumar, \& Doull, 2011; Zorc, \& Hall, 2010).

Bronchiolitis is the most common reason for hospitalization of children in many countries, challenging the economy and the staffing in pediatric departments. Respiratory syncytial virus (RSV) is the most common virus causing bronchiolitis, occurring in epidemics during winter months (Nagakumar, \& Doull, 2011; Zorc, \& Hall, 2010).

Pediatrics pleural effusion is an abnormality that frequently develops from the collection of fluids in the pleural space commonly caused by a primary phenomenon or secondary to a variety of disorders such as an infection. This accumulated fluid can originate from excessive filtration or defective absorption. Despite asymptomatic features in mild effusion, it may be accompanied by complications such as respiratory failure due to massive fluid accumulation, septicemia, bronchopleural fistula, pneumothorax, and pleural thickening (Wang, 1998). This study aimed to detect the correlation between RDW in children in PICU and respiratory diseases.

\section{MATERIALS AND METHODS}

We retrospectively analyzed all patients who were consecutively admitted to PICU at Tobruk Medical Center between January 2017 and January 2019. All patients under 16 years old with an available baseline RDW value on admission to PICU and needed respiratory support were eligible for inclusion.

Demographic data, laboratory values, cause of admission, complications, and outcome parameters were extracted for review from the PICU Patient files. We excluded patients who were transferred to another intensive care facility and thus lost to follow-up, those with ICU discharge within $24 \mathrm{hrs}$ after admission, those with hemoglobinopathies, those who received a blood transfusion prior to ICU admission, and neurologically dysfunction patients who needed oxygen therapy. Reference values for RDW in our hospital are between $11.6 \%$ and $14.6 \%$. For statistical analysis, the data were analyzed using Minitab Version 17 software. 


\section{RESULTS}

In this retrospective study, it was reported that males outnumbered females in addition to other demographic data that are listed in Table 1. Most of our patients were tachypneic, with a mean respiratory rate of $64.12 \pm 13.45$. The commonest cause of admission was bronchopneumonia, followed by acute broncholitis and aspiration pneumonia, as listed in Table 2 and Figure 1. Our results indicated respiratory retraction in most of the cases, grunting and retraction in $35 \%$, and cyanosis only in $28 \%$ of cases.Pulmonary infiltrations on chest $\mathrm{x}$-rays were in $62 \%$ of patients, while others had free chest x-rays. The mean of RDW, as mentioned in Table 3, was $14.499 \pm 2.612$, and Figure 2 shows the probability plot of RDW. Sepsis was the commonest complication reported in this study, followed by aspiration and other complications, as listed in Table 4. Nasal prongs were the commonest mode of oxygen therapy used with studied patients, as showed in Table 5.

Table(1): Demographic data of studied patients

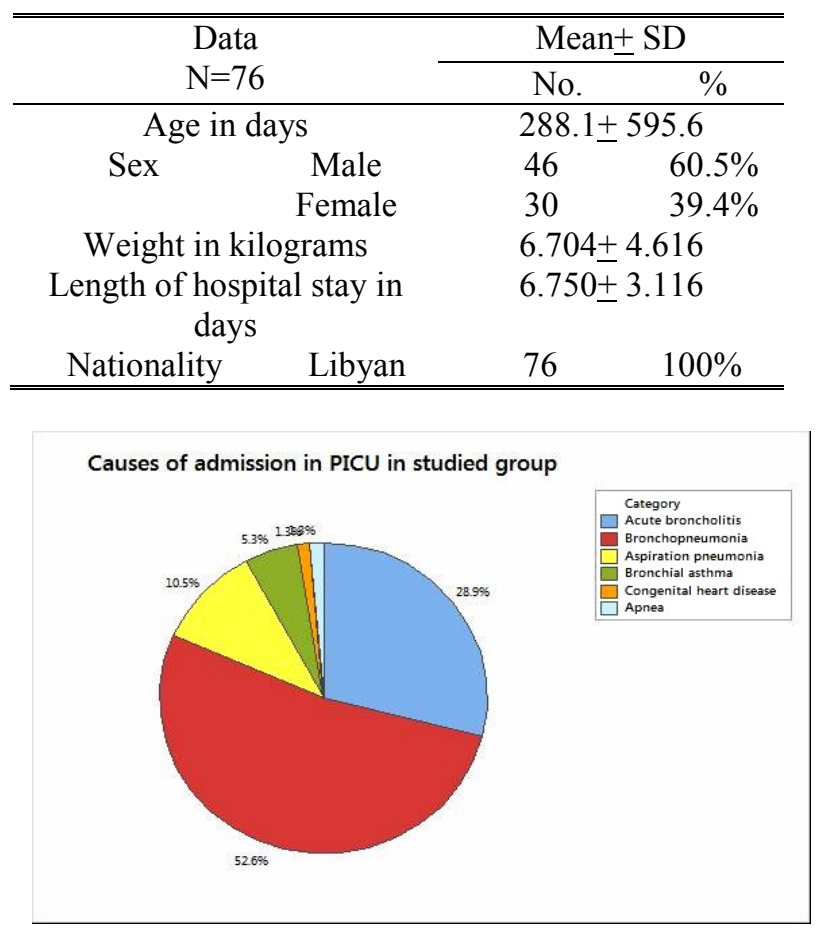

Figure :(1). Causes of admission in studied patients
Table 2: Causes of admission in studied patients

\begin{tabular}{cc}
\hline \hline Causes of admission & Percentage \% \\
\hline Bronchopneumonia & $52.6 \%$ \\
Acute Broncholitis & $28.9 \%$ \\
Aspiration Pneumonia & $10.5 \%$ \\
Bronchial Asthma & $5.3 \%$ \\
Apnea & $1.4 \%$ \\
Congenital Heart Dis- & $1.3 \%$ \\
eases & \\
\hline \hline
\end{tabular}

Table (3): Hematological indices of studied group

\begin{tabular}{cc}
\hline \hline Hematological indices & Mean \pm SD \\
\hline HB & $10.455 \pm 2.027$ \\
RBC & $4.075 \pm 2.389$ \\
MCV & $82.03 \pm 13.64$ \\
MCH & $28.75 \pm 8.97$ \\
MCHC & $33.92 \pm 10.59$ \\
WBC & $13.037 \pm 5.351$ \\
PLAT. & $398.5 \pm 150.4$ \\
RDW & $14.499 \pm 2.612$ \\
CRP & $13.20 \pm 10.34$ \\
\hline \hline
\end{tabular}

Table (4 ): Complications of patients

\begin{tabular}{cc}
\hline \hline $\begin{array}{c}\text { Complications of } \\
\text { our patients }\end{array}$ & Percentage \% \\
\hline Sepsis & $40.8 \%$ \\
Aspiration & $23.7 \%$ \\
Pneumothorax & $10.5 \%$ \\
Convulsion & $9.2 \%$ \\
Apnea & $7.9 \%$ \\
Pleural effusion & $6.6 \%$ \\
Renal failure & $1.3 \%$ \\
\hline \hline
\end{tabular}

In this study, most patients with respiratory diseases were discharged $98.6 \%$, and one patient transferred to another hospital for farther evaluation without any mortality reported

Table 5: Oxygen therapy in studied patients

\begin{tabular}{cccc}
\hline \hline \multirow{2}{*}{ Item } & \multicolumn{2}{c}{ No } & $\%$ \\
\cline { 3 - 4 } & & \multicolumn{2}{c}{ Mean \pm SD } \\
\hline \multirow{2}{*}{$\begin{array}{c}\text { Mode of O2 } \\
\text { therapy }\end{array}$} & Nasal prong & 46 & $60.5 \%$ \\
& Mask & 29 & $38.1 \%$ \\
Dechanical ven- & 1 & $1.3 \%$ \\
tilator & & \\
\hline \hline
\end{tabular}




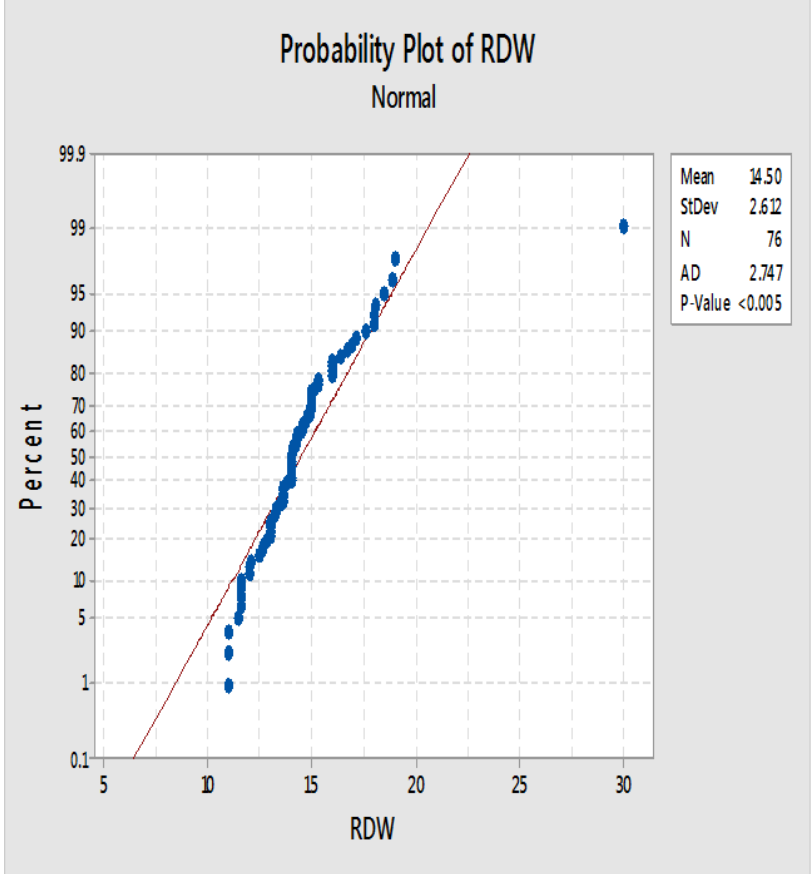

Figure(2): Probability plot of RDW

We found a strong correlation between RDW and respiratory signs of respiratory diseases with P-value (0.000) as listed in Table 6. Also, there was an association between RDW and the duration of oxygen therapy (Table 6) with a significant P-value. While no correlation was found between RDW and CRP as an inflammatory marker, with P-value (0.540) as listed in Table 7.

Table (6): Correlation between RDW and Respiratory signs and duration of oxygen therapy

\begin{tabular}{cccc}
\hline \hline $\begin{array}{c}\text { Respiratory } \\
\text { signs }\end{array}$ & $\begin{array}{c}\text { RDW } \\
\text { Mean } \pm \\
\text { SD }\end{array}$ & $\begin{array}{c}\text { 95\% CI for } \\
\text { difference }\end{array}$ & $\begin{array}{c}\text { P-Value } \\
\text { Mean }\end{array}$ \\
\hline Retraction, & $14.18 \pm$ & $12.888 ; 14.083$ & 0.000 \\
grunting \& & 2.77 & $\begin{array}{c}\mathrm{DF}=75 \\
10.253 ;\end{array}$ & \\
cyanosis & & $11.666)$ & \\
Duration of & & $\mathrm{DF}=128$ & \\
O2 therapy & &
\end{tabular}

Table (7): correlation between RDW \& CRP

\begin{tabular}{llll}
\hline \hline & RDW & $\begin{array}{l}95 \% \text { CI for } \\
\text { difference }\end{array}$ & P-Value \\
\cline { 2 - 4 } CRP & $12.94 \pm$ & $-3.72 ; 1.12$ & 0.540 \\
& 7.79 & & \\
\hline \hline
\end{tabular}

\section{DISCUSSION}

RDW at the time of PICU admission is associated with different validated parameters for respiratory diseases in our study of PICU patients. The need for oxygen by nasal prongs, masks, and mechanical ventilation in PICU patients are associated with RDW values on admission. Sincer has demonstrated a higher RDW in patients with COPD compared to a control group, even when corrected for known reasons for a high RDW such as folate, iron, or vitamin B12 deficiencies (Sincer et al., 2012). In (Tom et al., 2017) the RDW was elevated in $61 \%(n=74)$ of patients. While our study showed only $36.8 \%$ had elevated RDW. There is a significant correlation between respiratory signs of respiratory diseases and RDW. We study the demographical information and different patient comorbidities, which we commonly encounter in the ICU setting. This includes pneumothorax, pleural effusion, aspiration, sepsis, apnea, renal failure, and convulsion. Therapeutic interventions such as the use of steroids, oxygen, and the use of broadspectrum antibiotics were also studied.

Until recently, the value of RDW in children admitted to the PICU had not been reported. The relationship between RDW and organ failure was not studied specifically because only one patient developed respiratory failure and needed ventilator support. A recent study by Said et al. in critically ill children showed that admission RDW is associated with pediatric PICU mortality and morbidity, independent of illness severity (Said et al., 2017). RDW has shown utility as a biomarker associated with mortality in adult patients with both chronic illness (congestive heart failure, cancer, pulmonary hypertension, arteriosclerosis) and acute illness (pneumonia, sepsis, blood stream infections, stroke) (Ku NS et al., 2012 \& Lippi $\mathrm{G}$ et al.,2009). No correlation was found in this study between RDW and mortality. There are limited data testing the utility of RDW in critically ill children (Allen LA et al., 2010). The 
independent association of RDW with the outcome may imply that anisocytosis itself may be a possible causable factor in organ dysfunction (Bujak et al., 2015). Firstly, the presence of anemia is the most likely cause of a change in RDW (Bujak et al., 2015). Which is the reason we will correct our statistical model for this parameter in future researches, another factor potentially causing a change in RDW is vitamin D3 deficiency (Wang et al 2011). Vitamin D3 plays an important role in erythropoiesis and cell proliferation, so a small change in vitamin D3 concentration will affect bone marrow erythropoiesis. In our study, Vit D3 was not studied. Many confounding factors should be taken into account when considering the prognosis of a patient's disease, e.g. the underlying disease and inflammatory markers like CRP. RDW is possibly influenced or associated with these factors.

Several studies have compared RDW to other inflammatory markers such as interleukin 6, Creactive protein, as well as iron mobilization and anemia of chronic disease. In our analysis, we have included an inflammatory marker as CRP, and we found no correlation between CRP and RDW levels. We did use RDW values on admission, but it is possible that the values were already increased during the days preceding the admission. This study does not provide an answer as to whether an increase of RDW is a consequence of, or a reason for respiratory dysfunction. Regardless of these possible influencing factors, RDW is attractive as a pragmatic clinical biomarker for respiratory dysfunction by its low cost and universal availability compared to other proposed biomarkers. Further research is needed to confirm the relation between RDW and different organ systems dysfunction in pediatric populations. RDW could be a future prognostic tool or an additional biomarker for monitoring critically ill children.

\section{CONCLUSION}

We conclude from this retrospective study that there is a strong correlation between RDW and respiratory diseases as pneumonia, acute broncholitis, and others. There is also a strong relation between RDW and duration of oxygen therapy and length of hospital stay. We recommend farther studies to study the correlation between RDW and other organ diseases and vitamin D levels.

\section{ACKNOWLEDGEMENT}

I would like to thank fourth-year technology students of the anesthesia department for their help in data collection.

\section{REFERENCES}

Allen, L.A., Felker, G.M., Mehra, M.R., Chiong, J.R., Dunlap, S.H., Ghali, J.K., et al. (2010). Validation and potential mechanisms of red cell distribution width as a prognostic marker in heart failure. J Card Fail. 16:230-8.

Bessman, J. D., Hurley, E.L (1983). Groves MR. Nondiscrete heterogeneity of human erythrocytes: comparison of Coulter-principle flow cytometry and Soret-hemoglobinometry image analysis. Cytometry; 3:292-295.

Bujak, K., Wasilewski, J., Osadnik, T., Jonczyk, S., Kołodziejska, A., Gierlotka, M., et al. (2015). The Prognostic Role of Red Blood Cell Distribution Width in Coronary Artery Disease: A Review of the Pathophysiology. Dis

Markers. 824624.

Fontana, V., Spadaro, S., Bond, O., Cavicchi, F.Z., Annoni, F., Donadello, K., et al. (2017). No relationship between red blood cell distribution width and 
microcirculatory alterations in septic patients.

Grant, B.J.B., Kudalkar, D.P., Muti. P., McCann, S.E., Trevisan, M., Freudenheim, J.L., et al. (2003). Relation between lung function and RBC distribution width in a populationbased study. Chest. 124:494.

Hunziker, S., Celi, L.A., Lee, J., Howell, M.D. (2012). Red cell distribution width improves the simplified acute physiology score for risk prediction in unselected critically ill patients. Crit Care.16:R89.

Ku, N.S., Kim, H., Oh, H.J., Kim, Y.C., Kim, M.H., Song, J.E., et al. (2012). Red cell distribution width is an independent predictor of mortality in patients with Gram-negative bacteremia. Shock. 38: 123-127.

Lippi, G., Targher, G., Montagnana, M., Salvagno, G.L., Zoppini, G., Guidi, G.C. (2009). Relation between red cell distribution width and inflammatory biomarkers in a large cohort of unselected outpatients. Arch Pathol Lab Med. 133: 628-632.

Nagakumar, P., Doull, I. (2011). Current therapy for bronchiolitis. Arch Dis Child. 97: 827-830.

Otero, T.M., Canales, C., Yeh, D.D., Hou, P.C., Belcher, D.M., Quraishi, S.A. (2016). Elevated red cell distribution width at initiation of critical care is associated with mortality in surgical Intensive Care Unit patients. $J$ Crit Care.34:7-11.

Said, Q.S., Spinella, P.C., Hartman, M.E., Steffen, K.M., Jackups, R., Holubkov, R. (2017). RBC Distribution Width: Biomarker for Red Cell Dysfunction and Critical Illness Outcome?. Pediatr Crit Care Med. 18:134-142.

Sincer, I., Zorlu, A., Yilmaz, M.B., Dogan, O.T., Ege, M.R., Amioglu, G., et al.(2012).Relationship between red cell distribution width and right ventricular dysfunction in patients with chronic obstructive pulmonary disease. Heart Lung. 41:238-243.

Tom, S., Jozef, J.De, D.,Walter, V., and Philippe, G. J. (2017). Red cell distribution width (RDW) as a biomarker for respiratory failure in a pediatric ICU. J Inflamm (Lond).14: 12.

Wang, F., Pan, W., Pan, S., Ge, J., Wang, S., Chen, M. (2011). Red cell distribution width as a novel predictor of mortality in ICU patients. Ann Med. 43:40-6.

Wang, N.S. (1998). Anatomy of the pleura. Clin Chest Med. Jun; 19(2):229-40.

Yčas, J.W., Horrow, J.C., Horne, B.D. (2015). Persistent increase in red cell size distribution width after acute diseases: A biomarker of hypoxemia?. Clin Chim Acta. 448:107-117.

Zhang, Z., Xu, X., Ni, H., Deng, H. (2013). Red cell distribution width is associated with hospital mortality in unselected critically ill patients. $J$ Thorac Dis.5:730-6.

Zorc, J.J., Hall, C.B. (2010) Bronchiolitis: recent evidence on diagnosis and management. Pediatrics. 125: 342-349 


\title{
عرض توزيع الخلايا الحمراء (RDW) وأمراض الجهاز التنفسي في وحدة العناية المركزة للأطفال طبرق
}

\author{
نسرين جمال صالح الفريخ \\ كلبة الطب البشرى، قسم الأطفال، جامعة طبرق، طبرق، ليييا \\ تاريخ الاستلام: 31 ديسمبر 2019 / تاريخ القبول: 19 يوليو 2025 \\ https://doi.org/10.54172/mjsc.v35i1.225:Doi
}

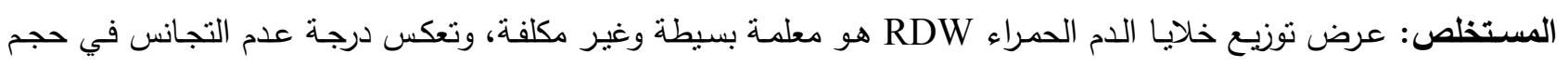

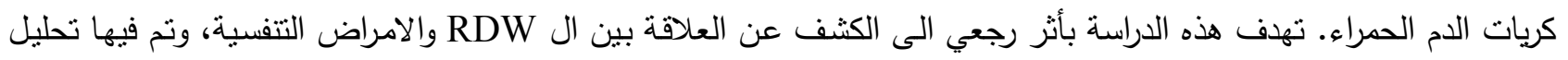

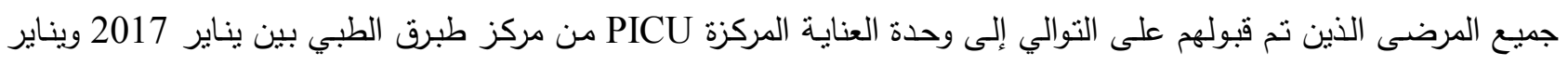

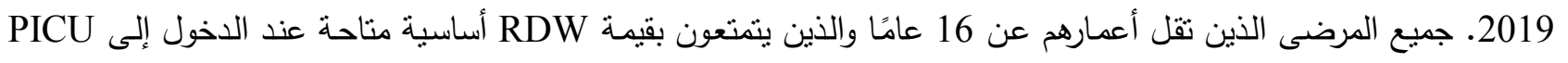

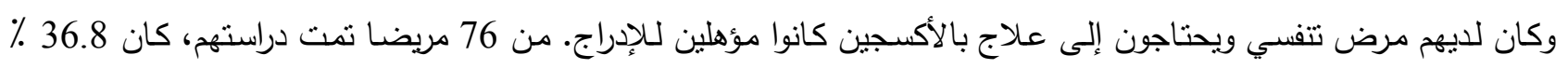

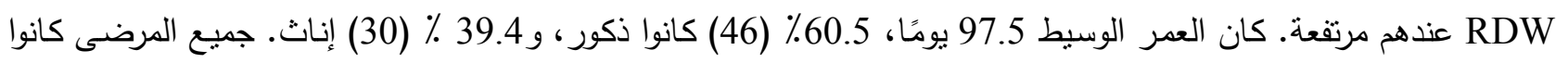

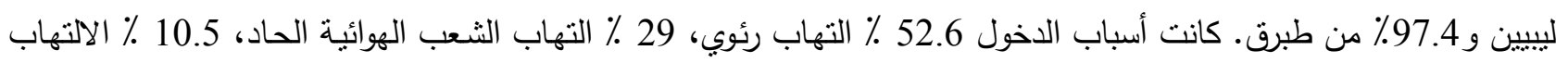

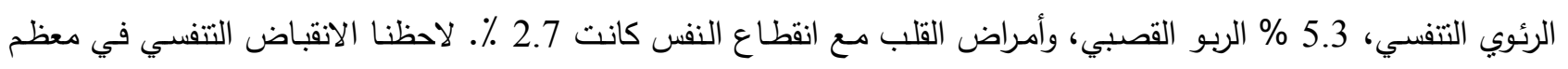

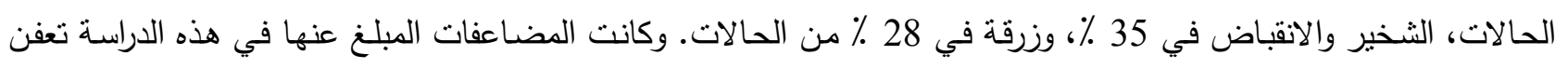

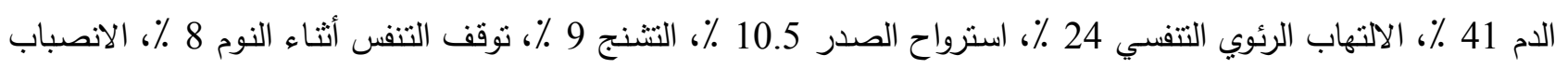

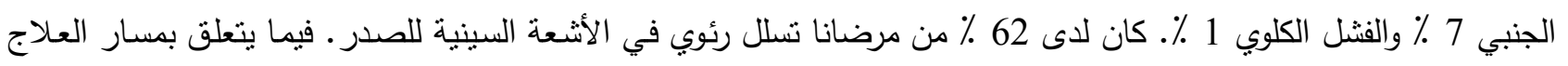

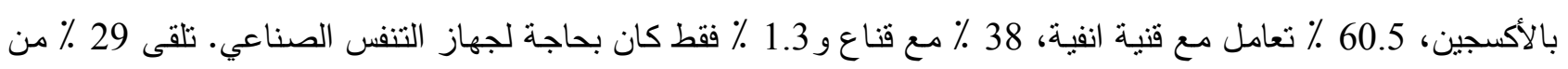

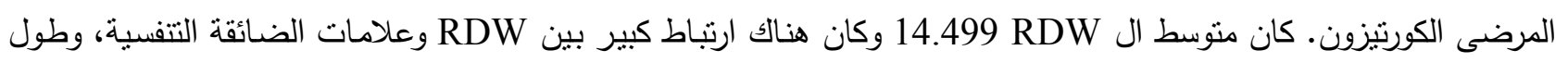

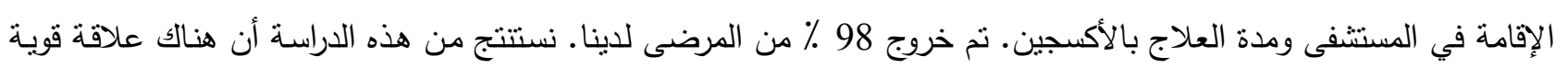

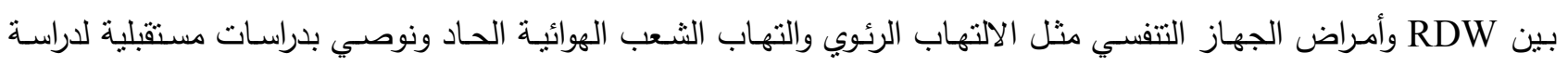
العلاقة بين RDW وأمراض الاعضاء الأخرى في الفئة العمرية للأطفال.

الكلمات المفتاحية: عرض توزيع الخلايا الحمراء، أمراض الجهاز التتفسي، وحدة العناية المركزة للأطفال. 